\title{
Evaluation of the Efficacy of Pramipexole for Treating Levodopa-induced Dyskinesia in Patients with Parkinson's Disease
}

\author{
Hiroya Utsumi ${ }^{1}$, Yasuyuki Okuma ${ }^{2}$, Osamu Kano ${ }^{3}$, Yutaka Suzuki ${ }^{4}$, Mutsumi Iijima ${ }^{5}$, \\ Hiroyuki Tomimitsu $^{6}$, Hideji Hashida ${ }^{7}$, Shin-ichiro Kubo ${ }^{8}$, Masahiko Suzuki ${ }^{9}$, \\ Kazunori Nanri ${ }^{10}$, Miyuki Matsumura ${ }^{11}$, Hidetomo Murakami ${ }^{12}$, and Nobutaka Hattori ${ }^{8}$ \\ on behalf of the Tokyo Parkinson's Disease Study Group
}

\begin{abstract}
Objective The long-term use of levodopa to treat Parkinson's disease (PD) is often limited by the development of motor complications (e.g. levodopa-induced dyskinesia, LID). We hypothesized that a non-ergot dopamine agonist with strong affinity for $\mathrm{D}_{3}$ dopamine receptors (pramipexole) may improve LID in patients taking an ergot $\mathrm{D}_{1} / \mathrm{D}_{2}$ dopamine agonist.

Methods Patients with PD and LID being treated with levodopa in addition to an ergot dopamine agonist were randomized to either a group in which pramipexole was added to current medications or a group in which the ergot dopamine agonist was switched to pramipexole. Dyskinesia was evaluated using Core Assessment Program for Surgical Interventional Therapies scores. The Unified Parkinson's Disease Rating Scale scores, Modified Hoehn and Yahr stages (at ‘on' time), Parkinson's Disease Questionnaire-39 scores and Clinical Global Impression-Improvement scores were also used for evaluation.

Results At 24 weeks, pramipexole alleviated LID with more efficiency in the switch group.

Conclusion Pramipexole may be a therapeutic option for treating LID because its effects on $\mathrm{D}_{3}$ dopamine receptors may balance the $\mathrm{D}_{1}$ dopamine receptor supersensitivity associated with LID.
\end{abstract}

Key words: dopamine agonist, dyskinesia, Parkinson's disease, pramipexole

(Intern Med 52: 325-332, 2013)

(DOI: 10.2169/internalmedicine.52.8333)

\section{Introduction}

Parkinson's disease (PD) is a movement disorder characterized by tremors, muscle rigidity, akinesia and disturbance of postural reflexes caused by the degeneration or death of nigrostriatal dopaminergic neurons (1). General pharmacological treatment aims to increase the dopamine levels in the brain. The oral administration of levodopa, a precursor for dopamine, is considered to be highly effective in the treatment of PD. However, the long-term use of levodopa is often complicated by the appearance of motor complications such as levodopa-induced dyskinesia (LID) (2). LID affects one-third of all patients with PD after two years of treatment and more than half of such patients after sustained exposure to levodopa for five years or longer (3-5). LID can

\footnotetext{
${ }^{1}$ Department of Neurology, Tokyo Medical University, Japan, ${ }^{2}$ Department of Neurology, Juntendo University Shizuoka Hospital, Japan, ${ }^{3}$ Department of Neurology, Toho University Omori Medical Center, Japan, ${ }^{4}$ Division of Neurology, Department of Medicine, Nihon University School of Medicine, Japan, ${ }^{5}$ Department of Neurology, Tokyo Women's Medical University, Japan, ${ }^{6}$ Department of Neurology and Neurological Science, Tokyo Medical and Dental University, Japan, ${ }^{7}$ Department of Neurology, Japanese Red Cross Medical Center, Japan, ${ }^{8}$ Department of Neurology, Juntendo University School of Medicine, Japan, ${ }^{9}$ Department of Neurology, Jikei University School of Medicine, Japan, ${ }^{10}$ Department of Neurology, Tokyo Medical University Hachioji Medical Center, Japan, ${ }^{11}$ Department of Neurology, Institute of Geriatrics, Tokyo Women's Medical University, Japan and ${ }^{12}$ Department of Neurology, Showa University, Japan

Received for publication June 8, 2012; Accepted for publication October 9, 2012
}

Correspondence to Dr. Nobutaka Hattori, nhattori@juntendo.ac.jp 
initially involve small involuntary movements that are barely noticeable but have the potential to develop into movements that cause exhaustion and fatigue, thus resulting in severe weight loss and immobility (6).

In the long-term management of $\mathrm{PD}$, treatment-associated dyskinesia may compromise effective dosing of antiparkinsonian medications. Initially, dose reduction or discontinuation of levodopa should be considered. Unfortunately, this option is often difficult, because it causes worsening of the PD symptoms and decreases the patient's quality of life (QOL) (2, 6-8). More effective strategies for managing dyskinesias are needed that do not lead to a worsening of PD.

Increased $D_{1}$ dopamine receptor-mediated neurotransmission in neurons of the direct striatal output pathway seems to underlie the development of LID. In a study of monkey brains, Aubert et al. determined the changes that occur in $\mathrm{D}_{1}$ and $\mathrm{D}_{2}$ dopamine receptors in the striata of animals with parkinsonian syndrome and in those with parkinsonian syndrome treated chronically with levodopa with or without dyskinesia compared with normal controls (9). While the $\mathrm{D}_{1}$ receptor expression is not related to dyskinesia, the sensitivity of individual $D_{1}$ receptors is linearly related to dyskinesia. Levodopa treatment was found to have no effects on the expression of $\mathrm{D}_{2}$ receptors, suggesting that the indirect pathway does not play a predominant role in LID.

We hypothesized that an imbalance in the $D_{1}$ and $D_{3}$ receptor function may play a key role in LID for the following reasons. First, $\mathrm{D}_{1}$ and $\mathrm{D}_{3}$ receptors are probably coexpressed in neurons of the direct pathway (9). Second, whereas Aubert et al. found that levodopa-induced $\mathrm{D}_{1}$ supersensitivity seems to cause LID, other animal studies have shown that $D_{3}$ receptor agonists can attenuate LID while maintaining the effects of levodopa treatment $(10,11)$. This alleviation of LID may be caused by $\mathrm{D}_{3}$ agonists restoring balance in the direct pathway.

Dopamine agonists can be categorized as ergot-derived (bromocriptine, cabergoline and pergolide) or non-ergotderived (ropinirole and pramipexole) (12). The aim of the present study was to test our hypothesis that the use of a non-ergot dopamine agonist with a strong affinity for $\mathrm{D}_{3}$ dopamine receptors (pramipexole) may improve LID in patients taking an ergot $D_{1}$ and $D_{2}$ dopamine agonist without affecting the PD symptoms.

\section{Materials and Methods}

\section{Patients}

This study included men and women aged 20 years or older who were diagnosed with PD and met the following criteria: LID (peak-dose dyskinesia); receiving levodopa therapy in combination with a $\mathrm{D}_{1} / \mathrm{D}_{2}$ dopamine agonist; and a Mini-Mental State Examination score of 24 or greater. Only patients with peak-dose dyskinesia were included because of the small-scale, exploratory nature of the study.
Participants with LID must have received the same dose and administration of drugs for PD for at least four weeks before the start of the study.

Patients who met the following criteria were excluded: a history of hypersensitivity to pramipexole; psychiatric symptoms such as confusion, hallucinations, delusions, agitation, delirium or abnormal behavior; complications such as serious cardiac disease, renal disease or hepatic disease; previous treatment with deep brain stimulation; pregnant or possibly pregnant or breastfeeding; and having participated in another clinical study within three months before providing informed consent.

The study was approved by the institutional committees on human research of all participating institutions and was conducted in accordance with the principles of the Declaration of Helsinki. All patients provided their written informed consent.

\section{Study design}

This multicenter, randomized, open-label, parallel-group comparison study was conducted between January 2007 and June 2009 at 12 institutions in Tokyo, Japan.

The patients were randomized to the following groups: 1) add-on group; pramipexole was added to the existing drug regimen for treatment of $\mathrm{PD}$ without changing the dose or administration of the other drugs, 2) switch group; the current dopamine agonist was switched to pramipexole. Once the patients were randomly allocated, the study was conducted in an open-label manner.

The treatment period totaled 24 weeks and consisted of two periods: period 1 lasted four weeks and period 2 lasted 20 weeks. Period 1 evaluated the effects of pramipexole on dyskinesia. Period 2 confirmed whether there were positive effects on dyskinesia.

In the add-on group, the patients started taking pramipexole at a dose of $0.5 \mathrm{mg} /$ day (after breakfast and dinner), increased to $0.75 \mathrm{mg} /$ day during week $2,1.0 \mathrm{mg} /$ day during week 3 and finally $1.5 \mathrm{mg} /$ day during week 4 . If dyskinesia disappeared during the uptitration period and the investigator considered that further uptitration was unnecessary, the dose at that time was set as the maintenance dose and the study treatment was continued up to week 4. If dose reduction was required, the dose was downtitrated to the level at which continuation of the study treatment was considered possible.

In the switch group, the dose of bromocriptine, pergolide or cabergoline was reduced by half, and treatment with pramipexole was started at a dose corresponding to the reduced dose (transition period, two weeks). We used a published method to determine the corresponding doses (13); the dose ratio of pergolide: cabergoline: pramipexole was 3 : 4:3. Thereafter, the remaining dose of bromocriptine, pergolide or cabergoline was discontinued, and, at the same time, the dose of pramipexole was increased to the level that corresponded to the discontinued dose. The study treatment was then continued for another two weeks. 


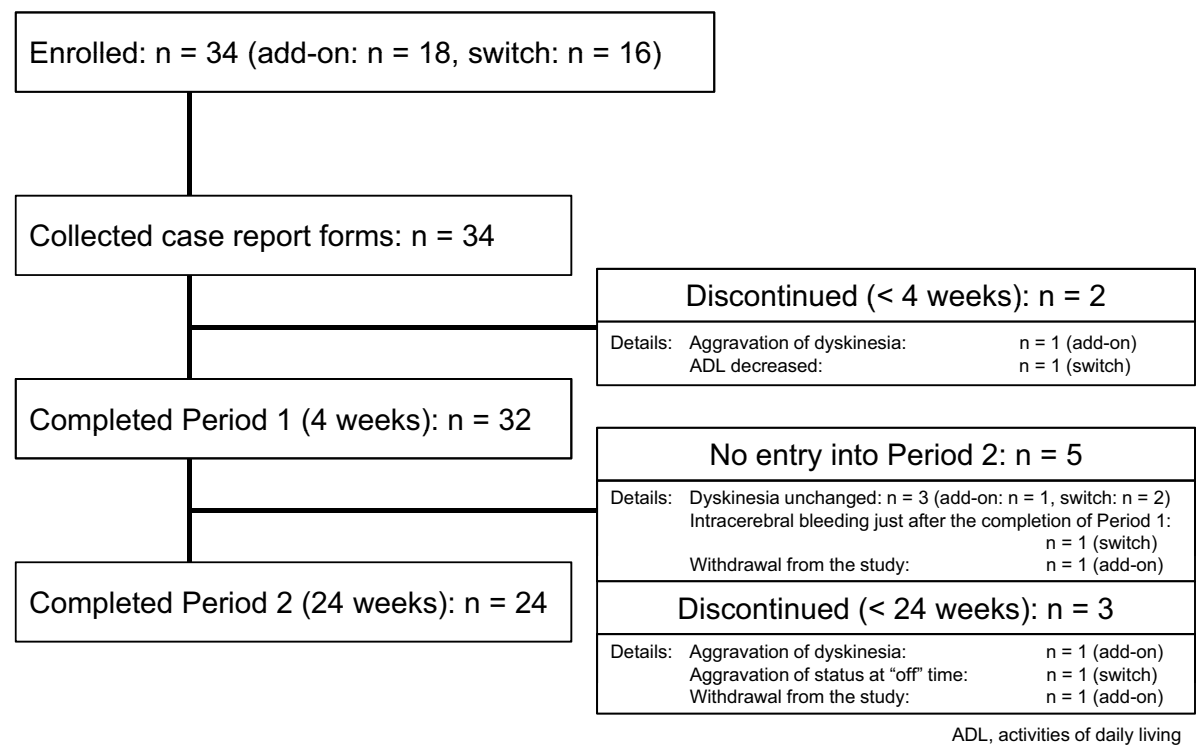

Figure 1. Patient disposition.

We calculated the levodopa equivalent dose received by patients in each group throughout the study.

In both groups, at the end of period 1, the patients without aggravation of symptoms judged according to the Clinical Global Impression-Improvement (CGI-I) scores and considered eligible for extension of the study treatment by the study investigators entered period 2.

The treatment dose at the end of period 1 (maintenance dose) was continued for 20 weeks. If symptoms related to PD were aggravated, the dose of pramipexole was increased. The maximum dose was $4.5 \mathrm{mg}$ per day ( $1.5 \mathrm{mg}$ after every meal). If dose reduction was required due to adverse effects, then the dose was downtitrated to the level at which continuation of the study treatment was considered possible by the attending physician. Downtitration was performed to avoid the development of neuroleptic malignant syndrome associated with an abrupt discontinuation of the treatment.

\section{Method of evaluation}

The primary method used to measure the effects of pramipexole on dyskinesia was evaluation of the changes in the total Core Assessment Program for Surgical Interventional Therapies (CAPSIT) score, which assesses the degree of improvement of dyskinesia. The CAPSIT scale assesses seven body parts to provide a score ranging between 0 and 28. It uses the motor activation tasks included in the Unified Parkinson's Disease Rating Scale (UPDRS) and/or finger tapping. The scale provides concurrent information regarding the status of PD as well as dyskinesias $(14,15)$ and is commonly used to evaluate the efficacy of surgical interventions, including deep brain stimulation of the subthalamic nucleus (16).

Further evaluations of the patients were performed using changes in the Modified Hoehn and Yahr stages (at 'on' time) to assess the level of disability, changes in the scores of UPDRS Parts II, III and IV (A, B) to follow disease pro- gression, changes in Parkinson's Disease Questionnaire-39 (PDQ-39) scores to evaluate QOL and changes in CGI-I scores to assess disease improvement.

\section{Statistical analyses}

The mean changes from baseline to the end of the treatment period were compared using Wilcoxon's test, and $\mathrm{p}<$ 0.05 (two-tailed) indicated statistical significance.

\section{Results}

\section{Patient characteristics}

A total of 34 patients were enrolled in the study, 18 of whom were randomized to the add-on treatment group and 16 of whom were randomized to the switched treatment group (Fig. 1). There were no significant differences between the groups with respect to the baseline characteristics of the patients (Table 1). All patients continued to receive levodopa throughout the study period. Other concomitant medications are shown in Table 2.

The mean last dosage of pramipexole was $1.7 \pm 1.0 \mathrm{mg} / \mathrm{day}$ overall, $1.2 \pm 0.4 \mathrm{mg} / \mathrm{day}$ in the add-on group and $2.1 \pm 1.2$ $\mathrm{mg} / \mathrm{day}$ in the switch group. There were no changes in the Modified Hoehn and Yahr stages (at 'on' time) throughout the study period.

The doses of levodopa were not changed, except in one patient in the switch group after pramipexole treatment. The mean dose of levodopa before and after pramipexole treatment was not significantly different in either the switch group or the add-on group (Table 3). Furthermore, the mean dose of levodopa was not significantly different between the switch group and the add-on group (Table 3). Data for the duration of levodopa treatment were unavailable. However, the durations of PD and dyskinesia were not significantly different between the add-on group and the switch group 
Table 1. Baseline Patient Characteristics $(n=34)$

\begin{tabular}{|c|c|c|c|c|c|}
\hline & & & \multicolumn{3}{|c|}{ Treatment method } \\
\hline & & & $\begin{array}{l}\text { Add-on } \\
(\mathrm{n}=18)\end{array}$ & $\begin{array}{c}\text { Switch } \\
(\mathrm{n}=16)\end{array}$ & $\mathrm{p}$ \\
\hline \multicolumn{6}{|l|}{$\operatorname{Sex}[\mathrm{n}(\%)]$} \\
\hline Male & & $12(35.3)$ & $6(33.3)$ & $6(37.5)$ & 1.000 \\
\hline Female & & $22(64.7)$ & $12(66.7)$ & $10(62.5)$ & \\
\hline Age (years) & Mean $\pm \mathrm{SD}$ & $67.9 \pm 6.4$ & $67.2 \pm 5.4$ & $68.8 \pm 7.5$ & 0.413 \\
\hline Outpatients $[\mathrm{n}(\%)]$ & & $34(100)$ & $18(100)$ & $16(100)$ & \\
\hline $\begin{array}{l}\text { Duration of Parkinson's } \\
\text { disease (years) }\end{array}$ & Mean \pm SD & $12.3 \pm 5.5$ & $12.4 \pm 5.3$ & $12.2 \pm 5.9$ & 0.986 \\
\hline $\begin{array}{l}\text { Duration of dyskinesia } \\
\text { (years) }\end{array}$ & Mean \pm SD & $3.5 \pm 3.5$ & $2.8 \pm 2.1$ & $4.2 \pm 4.5$ & 0.816 \\
\hline \multicolumn{6}{|l|}{$\begin{array}{l}\text { Coexisting diseases } \\
{[\mathrm{n}(\%)]}\end{array}$} \\
\hline Absent & & $19(55.9)$ & $11(61.1)$ & $8(50.0)$ & 0.730 \\
\hline Present & & $15(44.1)$ & $7(38.9)$ & $8(50.0)$ & \\
\hline \multicolumn{6}{|l|}{$\begin{array}{l}\text { History of other } \\
\text { diseases [n (\%)] }\end{array}$} \\
\hline Absent & & $24(70.6)$ & $14(77.8)$ & $10(62.5)$ & 0.457 \\
\hline Present & & $10(29.4)$ & $4(22.2)$ & $6(37.5)$ & \\
\hline \multicolumn{6}{|l|}{ Assessment scale } \\
\hline $\mathrm{H} \& \mathrm{Y}$ & Mean \pm SD & $2.72 \pm 0.77$ & $2.72 \pm 0.79$ & $2.72 \pm 0.77$ & 0.930 \\
\hline \multicolumn{6}{|l|}{ UPDRS } \\
\hline Total & Mean $\pm \mathrm{SD}$ & $32.45 \pm 16.14$ & $31.39 \pm 13.69$ & $33.73 \pm 19.10$ & 1.000 \\
\hline Part II & Mean $\pm \mathrm{SD}$ & $8.29 \pm 6.78$ & $7.89 \pm 6.62$ & $8.75 \pm 7.14$ & 0.719 \\
\hline Part III & Mean \pm SD & $17.45 \pm 10.39$ & $16.61 \pm 8.58$ & $18.47 \pm 12.47$ & 0.760 \\
\hline Part IV (A) & Mean $\pm \mathrm{SD}$ & $3.79 \pm 1.47$ & $3.89 \pm 1.32$ & $3.69 \pm 1.66$ & 0.860 \\
\hline Part IV (B) & Mean $\pm \mathrm{SD}$ & $2.97 \pm 1.53$ & $3.00 \pm 1.41$ & $2.94 \pm 1.69$ & 0.819 \\
\hline CAPSIT & Mean $\pm \mathrm{SD}$ & $6.76 \pm 3.30$ & $6.28 \pm 2.91$ & $7.31 \pm 3.72$ & 0.482 \\
\hline PDQ-39 & Mean \pm SD & $42.42 \pm 28.91$ & $42.55 \pm 30.93$ & $42.29 \pm 27.90$ & 0.681 \\
\hline
\end{tabular}

Table 2. Concomitant Antiparkinsonian Therapy in the 24-week Treatment Period $(n=34)$

\begin{tabular}{lrrrr}
\hline & $\mathrm{n}(\%)$ & \multicolumn{3}{c}{ Treatment method } \\
\cline { 3 - 5 } & & $\begin{array}{l}\text { Add-on } \\
(\mathrm{n}=18)\end{array}$ & $\begin{array}{c}\text { Switch } \\
(\mathrm{n}=16)\end{array}$ & $\mathrm{p}$ \\
\hline Levodopa & $34(100.0)$ & $18(100.0)$ & $16(100.0)$ & 0.957 \\
Dopamine agonist & $18(52.9)$ & $18(100.0)$ & $0(0.0)$ & \\
Anticholinergics & $7(20.6)$ & $5(27.8)$ & $2(12.5)$ & \\
Selegiline & $13(38.2)$ & $5(27.8)$ & $8(50.0)$ & \\
Amantadine & $15(44.1)$ & $8(44.4)$ & $7(43.8)$ & \\
Entacapone & $4(11.8)$ & $3(16.7)$ & $1(6.3)$ & \\
Droxidopa & $1(2.9)$ & $0(0.0)$ & $1(6.3)$ & \\
\hline
\end{tabular}

(Table 1).

The mean levodopa-equivalent dose was increased in the patients in the add-on group, although it was almost unchanged in the patients in the switch group because the study protocol specified that the doses of antiparkinsonian drugs should be unchanged during the administration of pramipexole. The patients in the add-on group received a mean levodopa-equivalent dose of $785.2 \mathrm{mg} /$ day at baseline, increased by approximately $9 \%(70 \mathrm{mg} /$ day $)$ to $856.0 \mathrm{mg} /$ day at the end of the study period. The patients in the switch group received a mean levodopa-equivalent dose of $596.8 \mathrm{mg} /$ day at baseline and $607.8 \mathrm{mg} /$ day at the end of the study period.

\section{Changes in total CAPSIT scores}

The total CAPSIT scores in the overall study population
Table 3. Levodopa Treatment before and after Pramipexole Treatment

\begin{tabular}{lcc}
\hline & \multicolumn{2}{c}{ Levodopa dose $[\mathrm{mg} /$ day $($ mean \pm SD) $]$} \\
\cline { 2 - 3 } & Before & After \\
\hline All & $457 \pm 193$ & $454 \pm 193$ \\
Switch group & $406 \pm 162$ & $400 \pm 160$ \\
Add-on group & $503 \pm 210$ & $503 \pm 210$ \\
\hline
\end{tabular}

$(n=34)$ were significantly reduced after 24 weeks of treatment ( $\mathrm{p}<0.01$ versus baseline) (Fig. 2), indicating improvements in dyskinesia. The significant reductions in the CAPSIT scores became apparent as early as week 2, with maximum reductions occurring at weeks 12 and 24 .

\section{Changes in total CAPSIT scores: the add-on group versus the switch group}

Despite significant reductions in the total CAPSIT scores at four weeks in the add-on group $(n=18)$, at 24 weeks, there were no significant changes compared with the baseline values (Fig. 3). In the switch group $(n=16)$, significant reductions in the total CAPSIT scores became apparent at week 4 and were maintained through weeks 12 and $24(\mathrm{p}<$ $0.01)$.

\section{Changes in UPDRS subscores}

In the overall study population, there were significant reductions in the UPDRS part III subscores at week 24 com- 


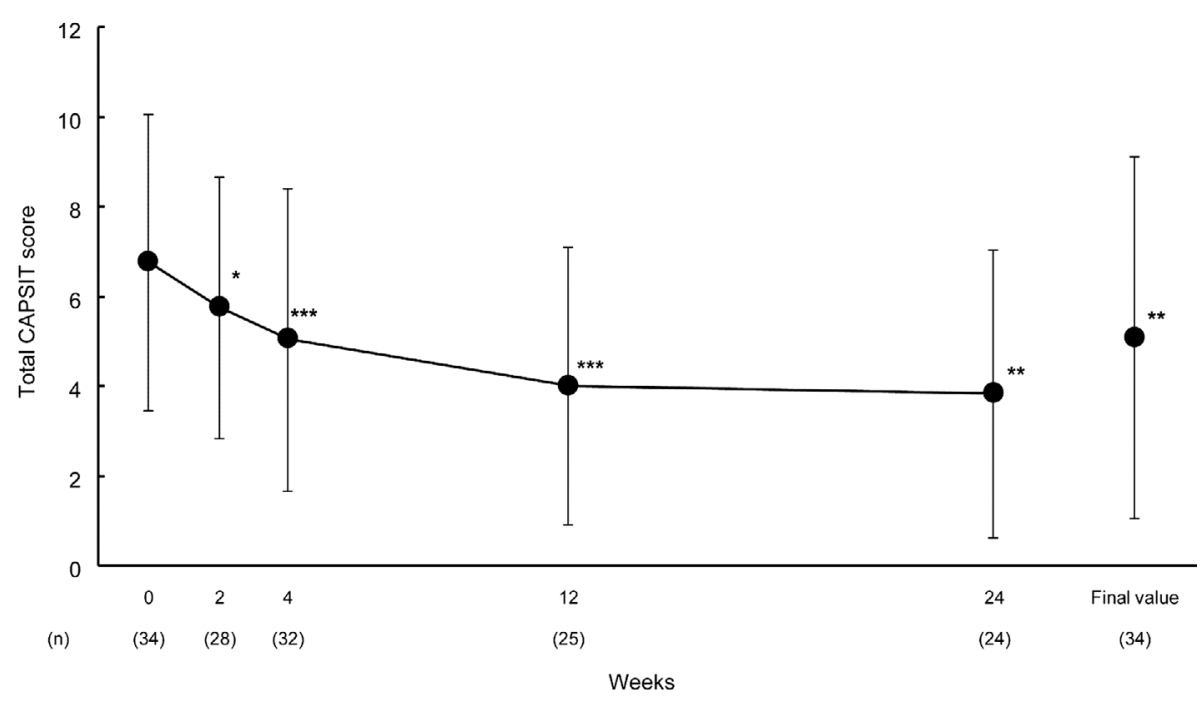

Figure 2. Changes in the Core Assessment Program for Surgical Interventional Therapies (CAPSIT) scores in the overall study population. The values are expressed as the mean \pm SD. ${ }^{*} \mathbf{p}<\mathbf{0 . 0 5},{ }^{* *} \mathbf{p}<\mathbf{0 . 0 1}, * * \mathbf{*}<\mathbf{0 . 0 0 1}$ (one-sample Wilcoxon's test for changes). To include data for all patients, missing values for patients who discontinued pramipexole during the treatment period were imputed using the last observation carried forward method to produce the final value.

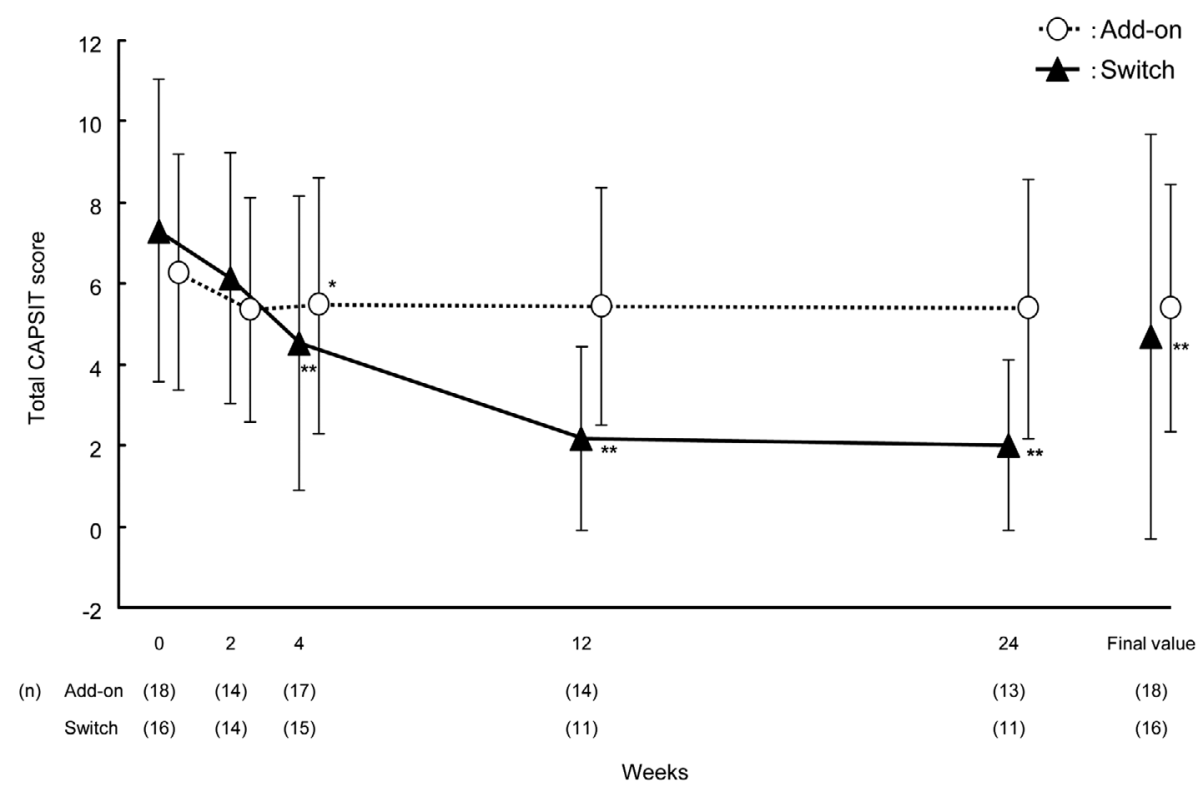

Figure 3. Changes in the Core Assessment Program for Surgical Interventional Therapies (CAPSIT) scores in the add-on and switch subgroups. The values are expressed as the mean \pm SD. *p $<0.05$, **p $<0.01$ (one-sample Wilcoxon's test for changes). To include data for all patients, missing values for patients who discontinued pramipexole during the treatment period were imputed using the last observation carried forward method to produce the final value.

pared with the baseline values $(\mathrm{p}<0.01)$ (Fig. 4), indicating improvements in PD motor symptoms. These reductions became apparent as early as week 2 and were maintained throughout the study period. There were no changes in the UPDRS part III subscores in the add-on group at week 24. However, in the switch group, there were significant reductions at all time-points $(\mathrm{p}<0.05)$.

In addition, there were reductions in the UPDRS part II subscores (at 'on' time) in the overall study population at week $24(\mathrm{p}<0.05)$. The trends in the changes in the UPDRS part II subscores were similar in the overall study population and in each group.

There were no changes in the UPDRS part IV subscores for dyskinesia (A) at week 24 in the overall study population. There was a downward trend toward clinical intraday fluctuations (B) in the overall study population (Fig. 5). By subgroup, both the add-on group and the switch group showed similar downward trends; however, the changes be- 


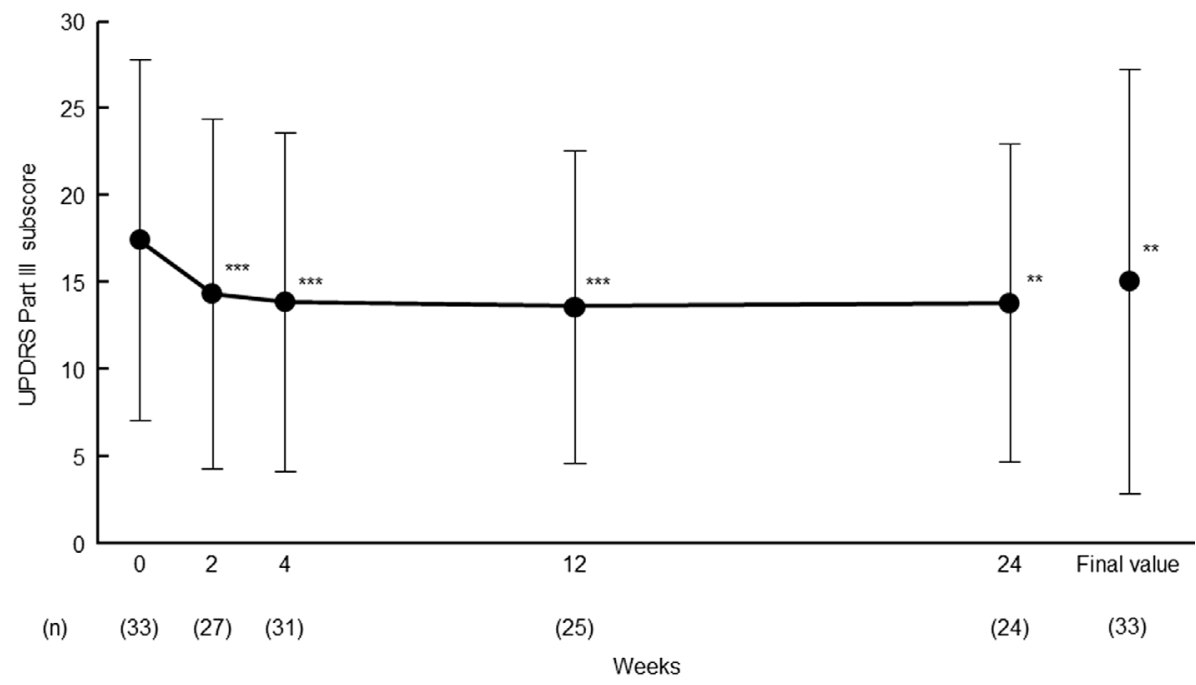

Figure 4. Changes in the Unified Parkinson's Disease Rating Scale (UPDRS) part III subscores (motor symptoms). The values are expressed as the mean \pm SD. $* * \mathbf{p}<0.01$, ***p $<0.001$ (one-sample Wilcoxon's test for changes). To include data for all patients, missing values for patients who discontinued pramipexole during the treatment period were imputed using the last observation carried forward method to produce the final value.

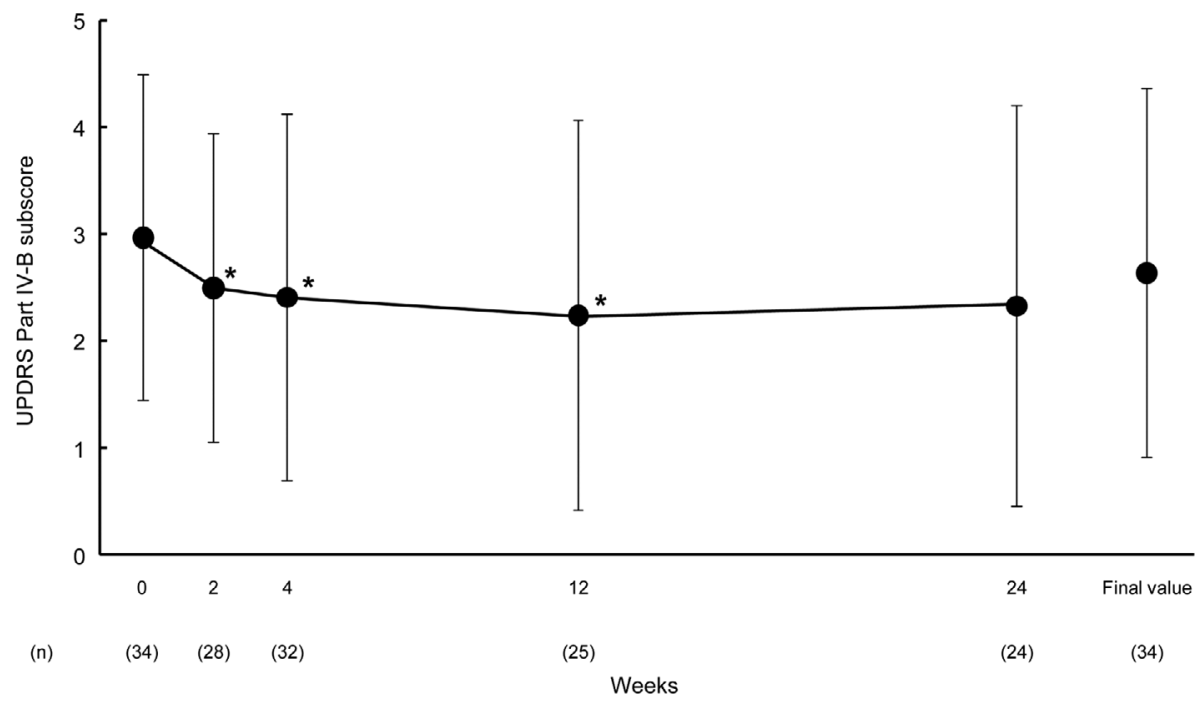

Figure 5. Changes in the Unified Parkinson's Disease Rating Scale (UPDRS) part IV-B subscores (clinical fluctuations). The values are expressed as the mean $\pm \mathrm{SD}$. * $\mathbf{p}<0.05$ (one-sample Wilcoxon's test for changes). To include data for all patients, missing values for patients who discontinued pramipexole during the treatment period were imputed using the last observation carried forward method to produce the final value.

tween the subscores at baseline and at week 24 were not significant for either subgroup.

\section{Changes in PDQ-39}

In the overall study population, there were significant reductions in the PDQ-39 scores at weeks 4 and 24 compared with the baseline values $(\mathrm{p}<0.01)$ (Fig. 6), showing improvements in QOL. There were no changes in the PDQ-39 scores in the add-on group at week 24. However, in the switch group, there were significant reductions at all timepoints $(\mathrm{p}<0.05)$.

\section{Physicians' overall impressions (CGI-I)}

The overall impressions of the study investigators at week 24 were that one patient $(3.0 \%)$ had improved, 15 patients had slightly improved $(45.5 \%)$ and there had been no changes in 13 patients $(39.4 \%)$. PD was slightly aggravated in four patients $(12.1 \%)$.

\section{Safety}

A total of three patients experienced adverse events (8.8\%): two in the add-on group $(11.1 \%)$ and one in the 


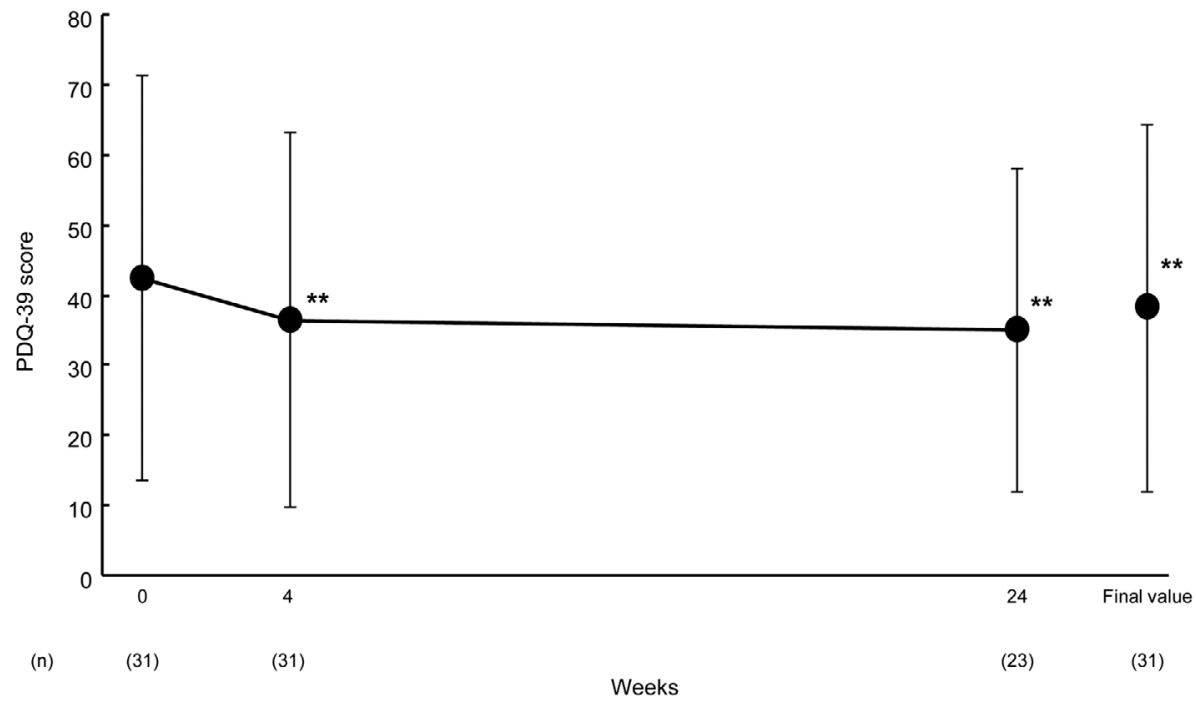

Figure 6. Changes in the Parkinson's Disease Questionnaire-39 (PDQ-39) scores. The values are expressed as the mean \pm SD. ${ }^{* *} \mathbf{p}<0.01$ (one-sample Wilcoxon's test for changes). To include data for all patients, missing values for patients who discontinued pramipexole during the treatment period were imputed using the last observation carried forward method to produce the final value.

switch group $(6.3 \%)$. Two patients in the add-on group developed aggravation of dyskinesias that were judged to be related to treatment with pramipexole. One patient in the switch group developed aggravation of 'off'-time status, which was judged to be an equivocal relationship to treatment with pramipexole.

\section{Discussion}

Understanding how dopamine agonists work with dopamine receptors is critical to finding a way to better deal with LID. However, management after the onset of LID is difficult and has not been fully established (6). The present study evaluated the efficacy of pramipexole, a non-ergot dopamine agonist, when either added to an existent drug regimen or switched with the existing drug in patients with LID who had been treated with levodopa and a dopamine agonist.

Addressing the balance and relationship of $D_{1}$ and $D_{3}$ dopamine receptors will help to solve the problems caused by LID. Because levodopa modifies the $\mathrm{D}_{1}$ receptor expression, sensitivity and integrity of the signaling cascade, $\mathrm{D}_{1}$ sensitivity per $D_{1}$ receptor is therefore linearly related to dyskinesia (9). Malik et al. conducted a study of tardive dyskinesia in Cebus monkeys to examine the role of $\mathrm{D}_{3}$ dopamine receptors in the $\mathrm{D}_{1} / \mathrm{D}_{3}$ imbalance and found an antidyskinetic effect of $\mathrm{D}_{3}$ dopamine agonists on $\mathrm{D}_{1}$ agonistinduced dyskinesia (10). The potential for the existence of a direct pathway between $\mathrm{D}_{1}$ and $\mathrm{D}_{3}$ dopamine receptors would explain $\mathrm{D}_{3}$ dopamine agonists having the ability to attenuate dyskinesia. The present study confirms that a preferential $\mathrm{D}_{3}$ agonist, pramipexole, attenuates LID without inducing any worsening of parkinsonism.

Given the significance of LID, standardized treatment needs to be developed in order to help alleviate the motor problems that result from LID while avoiding causing greater harm to the patient. The present study indicated that treatment with pramipexole may be effective in the management of motor complications in PD patients, including dyskinesia (as measured by CAPSIT scores) and wearing off (as measured by UPDRS part IV subscores). Pramipexole may be a therapeutic option for patients with LID who have been treated with levodopa. Pramipexole benefits stem from being a non-ergot dopamine agonist that has a strong affinity for $\mathrm{D}_{3}$ dopamine receptors, resulting in the improvement of LID without affecting PD symptoms. The results from both the add-on group and the switch group revealed that pramipexole effectively treated LID.

Patients who were switched to pramipexole experienced greater improvements in LID compared with those who had pramipexole added to their existing treatment regimen. This finding may be explained by the continued effects of the $D_{1}$ agonist in the add-on group, which may have reduced the balancing effect of pramipexole. A higher dose of pramipexole may have been more effective in the add-on group.

In the present study, pramipexole did not worsen PD symptoms, as measured by the UPDRS scores. Furthermore, considering that the UPDRS part IV subscores for intraday fluctuations showed a downward trend, treatment with pramipexole may be effective in the management of wearing off symptoms. Additionally, pramipexole significantly improved the patients' QOL, as measured by the PDQ-39 scores. The overall safety was good in both groups.

One limitation associated with our study is that although the patients were randomly assigned to the add-on and switch groups, they received open-label therapy. There is a potential bias favoring new treatment. Further evaluation in a large-scale double-blind study is needed, although the re- 
sults of previous studies support the direction of our research.

\section{Author's disclosure of potential Conflicts of Interest (COI).} Utsumi H: Advisory role, Novartis, Pfizer, GlaxoSmithKline, Sanofi-Aventis, Nihon Medi-Phisics Co., Otsuka Pharmaceutical Co., Kowa Pharmaceutical Co., Dainippon Sumitomo Pharm Co. and Takeda Pharmaceutical Co. Okuma Y: Advisory role, Boehringer Ingelheim, GlaxoSmithKline, Novartis, FP Pharmaceutical Corp., Otsuka Pharmaceutical Co. and Dainippon Sumitomo Pharm Co. Suzuki M: Advisory role, Boehringer Ingelheim, GlaxoSmithKline, Novartis, Pfizer, MSD and DaiichiSankyo Co. Hattori N: Advisory role, Boehringer Ingelheim, GlaxoSmithKline, Novartis, Schering-Plough, FP Pharmaceutical Corp., Kyowa Hakko Kirin Co. and Otsuka Pharmaceutical Co.; Honoraria, Nippon Boehringer Ingelheim; Research funding, Nippon Boehringer Ingelheim.

\section{References}

1. National Collaborating Centre for Chronic Conditions. Parkinson's Disease: National Clinical Guideline for Diagnosis and Management in Primary and Secondary Care. Royal College of Physicians, London, 2006.

2. Del Sorbo F, Albanese A. Levodopa-induced dyskinesias and their management. J Neurol 255 (Suppl 4): 32-41, 2008.

3. Parkinson Study Group. A randomized controlled trial comparing pramipexole with levodopa in early Parkinson's disease: design and methods of the CALM-PD study. Clin Neuropharmacol 23 : 34-44, 2000.

4. Rascol O, Brooks DJ, Korczyn AD, De Deyn PP, Clarke CE, Lang AE; 056 Study Group. A five-year study of the incidence of dyskinesia in patients with early Parkinson's disease who were treated with ropinirol or levodopa. N Engl J Med 342: 1484-1491, 2000.

5. Poewe WH, Lee AJ, Stern GM. Low-dose L-dopa therapy in Parkinson's disease: a 6-year follow-up study. Neurology 36: 1528-1530, 1986.

6. Thanvi B, Lo N, Robinson $\mathrm{T}$. Levodopa-induced dyskinesia in Parkinson's disease: clinical features, pathogenesis, prevention and treatment. Postgrad Med J 83: 384-388, 2007.

7. Jankovic J, Stacy M. Medical management of levodopa-associated motor complications in patients with Parkinson's disease. CNS Drugs 21: 677-692, 2007.

8. Barone P. Clinical strategies to prevent and delay motor complications. Neurology 61 (Suppl 3): S12-S16, 2003.

9. Aubert I, Guigoni C, Håkansson K, et al. Increased $\mathrm{D}_{1}$ dopamine receptor signaling in levodopa-induced dyskinesia. Ann Neurol 57: 17-26, 2005.

10. Malik $P$, Andersen MB, Peacock $L$. The effects of dopamine $D_{3}$ agonists and antagonists in a nonhuman primate model of tardive dyskinesia. Pharmacol Biochem Behav 78: 805-810, 2004.

11. Bézard E, Ferry S, Mach U, et al. Attenuation of levodopainduced dyskinesia by normalizing dopamine $\mathrm{D}_{3}$ receptor function. Nat Med 9: 762-767, 2003.

12. Kvernmo T, Härtter S, Burger E. A review of the receptor-binding and pharmacokinetic properties of dopamine agonists. Clin Ther 28: 1065-1078, 2006.

13. Stewart D, Morgan E, Burn D, et al. Dopamine agonist switching in Parkinson's disease. Hosp Med 65: 215-219, 2004.

14. Defer GL, Widner H, Marié RM, Rémy P, Levivier M. Core assessment program for surgical interventional therapies in Parkinson's disease (CAPSIT-PD). Mov Disord 14: 572-584, 1999.

15. Melamed E, Olanow CW, Nutt JG, Lang AE. Dyskinesias assessment workshop: reports from the working groups. Mov Disord $\mathbf{1 4}$ (Suppl 1): 69-73, 1999.

16. Portman AT, van Laar T, Staal MJ, Rutgers AWF, Journee HL, Leenders KL. Chronic stimulation of the subthalamic nucleus increases daily on-time without dyskinesia in advanced Parkinson's disease. Parkinsonism Relat Disord 12: 143-148, 2006.

(C) 2013 The Japanese Society of Internal Medicine http://www.naika.or.jp/imonline/index.html 